\title{
Study of Family Preferences of Orphan and Normal Children
}

\section{through Family Drawings}

\author{
G. Koteswaraiah ${ }^{1}$
}

\begin{abstract}
:
Family preferences of orphan and normal children were studied using family drawing technique. The sample of the study consisted of 105 orphan and 100 normal children. The results of the study revealed that there are significant differences between orphan and normal children in their preferences with respect to 'sequence', 'grouping', 'size' and 'inclusion' of different family members in their drawings. Highest percentage of orphan children preferred to draw brother and sister figures 'first' in the sequence of family drawings. But majority of normal children preferred to draw their self figure first, followed by father and brother in the sequence of family drawings. Majority of normal children drew all their family members' figures in to one ' group'. More orphan than normal children included sister figure, but more normal then orphan children included self figure in their family drawings.
\end{abstract}

Keywords: Family, Family Drawing, Orphan Children and Family Preferences.

Family is the most influential social agent. Through family relationships especially relationships with parents, the child learns to conform to group standards, modes and traditions and to cooperate with others (Freeman \& Showel,1953). The family is important principally, because of its strategic role in transmitting to its off spring the conceptions of social realities that parents have learned from their own experiences and strategies for dealing with problems of life (Kohn, 1972). During the last four to five decades the family in India has undergone phenomenal transformations-they involve both structural and attitudinal dimensions that have resulted in altered interpersonal relationships among the members who constitute the family and changes in family obligations in child-rearing and socialization processes. There is a distinct shift in family structure from an extended-kin to a primary-kin system (Sinha,1982).

${ }^{1}$ Reader in Psychology, Govt. College for Men (Autonomous), KADAPA, YSR District. Andhra Pradesh,

(C) 2015 I G. Koteswaraiah; licensee IJIP. This is an Open Access Research distributed under the terms of the Creative Commons Attribution License (http://creativecommons.org/licenses/by/2.0), which permits unrestricted use, distribution, and reproduction in any Medium, provided the original work is properly cited. 


\section{Study of Family Preferences of Orphan and Normal Children through Family Drawings}

In home, the child gains his first knowledge of the world and the people in it. Under the guidance of his parents he develops the ability to live with his family first and later to function as a member of a school or other social group. A favourable home is one in which there is good emotional balance. The child rightfully can expect that his physical and psychological needs will be met in home. Unfortunately, not all homes offer an atmosphere in which the developing child can thrive. Absence of one parent, constant bickering among family members, sibling rivalry, too strict discipline or too permissive attitude of the parents and other unfavourable conditions that may exist in the home can deny the child's rightful social heritage. Good home atmosphere is provocative of ease of child adjustment. Not all members of the family exert similar influence on children. The emotional distance and relationship that exists between the child and family members determine the level of influence that family members exert on the child. A home that is broken by divorce, the death or absence of one parent or both, or both parents working outside the home has significant influence on the life of a child and create much emotional disturbance and conflict in a child (Jackson,1950).

An important problem group among children is the orphans. Orphans are those who are deprived of one or both parents by death. Such children are deprived of proper clothing, sufficient food, education and spiritual advantages. Children can't really grew-up without some adult care. In the Indian society, care is taken of orphans in most cases by joint family members and other relatives. Even so, quite a few orphans are left to institutional care where they have more or less deprived of ordinary mothering. Institutions today vary considerably in their facilities, but even good institutional care is likely to fall short of desirable home environment in terms of stimulation, guidance and affectionate relationships. The actual nature and extent of damage the child experience due to parental deprivation depends upon the age at which deprivation first occurs, the extent and duration of the deprivation, the substitute care, if any, that is provided and constitutional make up of the infant. Studies have compared the development of the orphans with that of children reared at home and found that institutionalized children to be retarded in sensorimotor, language learning and social development (Yarrow,1965).

Children can communicate freely their inner feelings non-verbally than verbally. Their internal state of mind can be observed successfully through non-verbal communication. In the verbal communication, due to some inhibitions, difficulties in manipulation of language and immature verbal development, children can't express their feelings properly. Children express their ideas and feelings very freely through their play and drawings. Drawings were used as a technique to assess schizophrenic children (Montague, 1951), as a measure of cognitive development in children (Goodenough, 1926) and to understand the attitudes and emotions of children (Kelly, 1984). One of the central assumptions of the drawing procedure is that many important aspects of personality are not available to conscious self-report and thus questionnaires and inventories are of limited value. To obtain an accurate view of person's inner world, it is necessary to somehow circumvent unconscious defences and conscious resistances. 


\section{Study of Family Preferences of Orphan and Normal Children through Family Drawings}

To assess inter-personal relationships, several variations of projective drawings have involved the subject depicting groups of significant people in his or her environment. Hulse(1951), has developed the Draw-A-Family (DAF), in which subjects drew a picture of their whole family. To assesses the ongoing aspects of family relations, Burns(1987), developed Kinetic Family Drawings(KFD), in which subjects are required to draw their whole family doing some activity. Family drawing method was successfully used with Indian children also (Badhramani, etal. 1993). Family drawings is an expressive technique and concerned with specific content and relationships within families. It is very useful in the case of children who usually have greater difficulties than adults in articulating how they feel about relationships.

The family conditions are different for orphan and normal children. Owing to the differences in family conditions it is assumed that the family preferences of orphan and normal children may also differ. Hence, in the present investigation an attempt is made to study whether orphan and normal children differ with respect to their family preferences using family drawing technique. The family drawings will serve as a projective tool in the assessment of family preferences of orphan and normal children.

\section{HYPOTHESES:}

If the child is instructed to draw a picture of his/her family, the child draws the first figure of his/her family members, whom he most likely be with a sense of belonging, concern, etc. generally, normal children prefer to draw their parents first followed by others, because they live with their parents and feel close to them. Whereas, orphan children do not have their parents, they would not draw their parents first. Hence, it is hypothesized that:

1) There would be significant difference between orphan and normal children in their preference to draw their family members 'first'.

Children, when they perceive the entire family as a unit, they draw their family members in to one group or two groups. It is expected that normal children would draw their family members in to one or two groups. The orphan children do not think about their family as a unit, because they lack parents, they generally place their family members in to separate units or draw themselves lonely. In view of the above it is hypothesized that:

2) There would be significant difference between orphan and normal children in the 'grouping' of different family members in their drawings.

The largest figures and those drawn first are likely to $b$ e perceived by the children as more important and powerful than figures drawn smaller or at the last. Normal children draw their parents as larger than orphan children. Hence it is hypothesized that:

3) There would be significant difference between orphan and normal children in depicting the size of the different family members as the 'largest' figure.

In the case of inclusion of different family members in their drawings normal children are expected to include all their family members whom they think as a unit. They include parents and siblings in their drawings more than the other family members. It is not so in the case of orphan 
children. The orphan children can't conceive of a unitary family as they had no parents and they live outside the home environment. Hence it is hypothesized that:

4) There would be significant difference between orphan and normal children in the 'inclusion' of different family members in their drawings.

\section{SAMPLE:}

The sample of the study constituted of 105 orphan children and 100 normal children. Among the orphans the boys are 74 and girls are 31 . Their age ranges from 6-20 years. 70 boys and 30 girls constitute the normal children and their age ranges from 6-15 years. All the subjects were studying $1^{\text {st }}$ to $10^{\text {th }}$ standard in their respective schools. The orphan children were selected from Sri Venkateswara Balamandir school and Hostel for Orphan children. It is managed by the Titumala Tirupati Devastanams (TTD), Tirupati. The normal children were selected from local municipal schools in Tirupati.

The age range of the normal children 6-15 years does not match with that of orphan children. It is because whenever the orphan children are admitted in the respective institution, they are put in the first class irrespective of their age. As a result of this in orphan group, it is found that a child who is 10 years studying $1^{\text {st }}$ class. In the normal group a child who is 10 year old would be in the $5^{\text {th }}$ class. Orphan children suffer from lack of parental care. Taking all these aspects into account the marginal age disparity between orphan and normal children is considered justified for the purpose of psychometric and sampling characteristics.

\section{ADMINISTRATION OF THE TEST:}

Drawing of the family members is the technique used in the present investigation. The orphan children were met in their hostels during study hours in the evening in small groups of 10 children each. The normal children were met in a separate class room of about 10 students each, in the absence of their teacher. All the normal and orphan children have given a drawing sheet and pencil each and were asked to draw their family members' figures. No other information or instructions-like who are all there in the family, how many figures to draw, were given to the children. They were asked to finish their drawing in about 30 minutes of time. After they finished drawing each one of them was asked to return the sheet, name the order in which they have drawn different family members' figures etc. All particulars regarding age, class, gender of each child was marked on their respective drawing sheet.

\section{SCORING:}

Each drawing sheet was scored for the 4 pre-determined criteria or aspects. They are: 1) Sequence(First drawn figure), 2)Grouping, 3)Size( The largest figure drawn) and 4)Inclusion of family members. The above criteria were taken with the assumption that they will provide necessary information about family preferences of children.

1) Sequence (First drawn figure): The figure the child first drawn on the sheet is taken as 'first' drawn figure of family drawings. It is classified in to a) Self, b) Mother, c) Father, d) Brother, e) 


\section{Study of Family Preferences of Orphan and Normal Children through Family Drawings}

Sister, f) Grandparents, g) Others. Others means other than close family members mentioned above from ' a to f' like aunts, uncles, cousins and so on.

2 Grouping: The child might draw his family members in to groups, the number of groups they draw is called 'grouping'. The different categories in grouping are classified as-a) All in one, b) Two groups, c) Three groups, d) Divergence, e) Separate compartments, f) Does not apply. If a few members are grouped and a few are drawn apart it will be 'divergent'. If one single figure is drawn then that grouping is considered as 'does not apply' category.

3) Size: While drawing different members of his family if the child draws one among them as the biggest in comparison with others, it is termed as the 'largest'. When the child draws only a single figure then, it is considered as 'does not apply'. The different categories in the largest size figure drawn are: a) Self, b) Mother, c) Father, d) Brother, e) Sister, f) Grandparents, g) others, h) does not apply and i) all equal size.

4) Inclusion of family members: While drawing the family members children include different family members in their drawings, this is called 'inclusion'. The categories in the inclusion of family members are: a) Self, b) Mother, c) Father, d) Brother, e) Sister, f) Grandparents, g) Others and h) Does not apply.

The percentage of orphan and normal children preferring to draw different categories of figures on each of the above 4 aspects of family drawing were calculated. The differences of the percentages and the values of significance of difference between orphan and normal children were calculated using the test of significance.

\section{RESULTS:}

Percentages of orphan and normal children preferring to draw a) different family members 'first', b) family members into different 'groups', c) family members' figures as the 'largest' in size, and d) to 'include different family members and also the values of significance of the differences are presented in tables 1 to 4 respectively.

With respect to preferring to draw different family members 'first', the highest percentage of orphan children $(36.19 \%)$ preferred to draw the sister figure first, followed by brother figure $(33.33 \%)$, self, father, grandparents, others $6.66 \%$ each and mother $3.80 \%$ in that order. Comparatively the highest percentage of normal children $(26.00 \%)$ preferred to draw the 'self' first, next father figure $(23.00 \%)$, brother figure $(22.00 \%)$, sister figure $(12.00 \%)$, others $9.00 \%$, mother figure $5.00 \%$ and grandparents $3.00 \%$ in that order. However, orphan and normal children differ significantly from each other with respect to drawing 'first' figure of 'self' $(\mathrm{t}=3.81, \mathrm{p}<0.01)$, 'father' $(\mathrm{t}=3.19, \mathrm{p}<0.01)$ and 'sister' $(\mathrm{t}=4.08, \mathrm{p}<0.01)$ only. The other differences between orphan and normal children with respect to drawing different other categories family members 'first' are not significant. In the light of the results obtained with respect to the 'first' drawn figure, the hypothesis that "there would be significant difference between orphan and normal children in their preference to draw their family members 'first' is partially accepted. 


\section{Study of Family Preferences of Orphan and Normal Children through Family Drawings}

In the case of drawing the family members in to different groups, the highest percentage of orphan children $(43.80 \%)$ draw their family members in to 'does not apply' category, followed by 'all in one' category (24.76\%), 'two groups' (22.85\%), 'divergence' category (5.71\%), 'three groups' $(1.90 \%)$ and 'separate compartments' (0.95\%). Among the normal children the highest percentage (40.00\%) have drawn their family members in to 'all in one' group, followed by $35.00 \%$ in 'does not apply', $23.00 \%$ 'two groups', 1.00\% 'three groups' and $1.00 \%$ 'divergence' in that order. None of the normal children have drawn their family members in 'separate compartments' category. However, orphan and normal children differ significantly from each other with regard to drawing family members 'all in one group' $(\mathrm{t}=2.36, \mathrm{p}<0.05)$ and in to 'divergence' group $(\mathrm{t}=2.50, \mathrm{p}<0.05)$ only. The other differences between orphan and normal children with regard to drawing their family members in to different 'groups' are not significant. From the preceding results with respect to 'grouping' of different family members, the hypothesis that "there would be significant difference between orphan and normal children in the 'grouping' of different family members in their drawings" is partially accepted.

With respect to drawing of different family members' figures as the 'largest' in size, $43.80 \%$ of orphan children have drawn the family members into 'does not apply' category, followed by $17.52 \%$ have drawn grandparents as largest in size, $14.28 \%$ all equal, $8.57 \%$ brother and sister each, $3.80 \%$ other, $2.02 \%$ father and $1.90 \%$ self figure as the largest in size. Among the normal children, the highest percentage $38 \%$ have drawn only one figure, i.e., does not apply, followed by $13 \%$ all equal, $12 \%$ self, $10 \%$ mother, $9 \%$ father, $6 \%$ brother $5 \%$ grandparents and $3 \%$ sister figures as the largest in size. However, orphan and normal children differ significantly for their preference in drawing different family members' figures as the 'largest' in size with respect to self $(t=2.90, p<0.01)$, mother $(t=2.00, p<0.05)$ and grandparents $(t=3.15, p<0.01)$ only. The other differences between them with regard to other categories in depicting the 'size' of different family members' figures are not significant. In view of the results obtained above with respect to depicting the size of different family members, the hypothesis that "there would be significant difference between orphan and normal children in depicting the size of different family members as the largest figure" is partially accepted.

With respect to the preferences of orphan and normal children in the inclusion of different family members their drawings, the highest percentage $(57.14 \%)$ of orphan children included sister figure, followed by brother $(45.71 \%)$, father $(22.85 \%)$, grandparents $(16.19 \%)$,mother $(15.23 \%)$, self $(13.33 \%)$, others $(11.42 \%)$. In the case of normal children the highest percentage $(45.00 \%)$ have included brother figure, followed by self figure $43.00 \%$, father $29 \%$, sister $27 \%$, mother $19 \%$, grandparents $10 \%$ and others $13 \%$ in that order. However, orphan and normal children differ significantly with respect to inclusion of 'self' $(\mathrm{t}=4.80, \mathrm{p}<0.01)$ and the inclusion of 'sister' $(\mathrm{t}=4.42, \mathrm{p}<0.01)$ in their family drawings. But they do not differ significantly on other categories of the inclusion of different family members. From the preceding results with respect to inclusion of different family members the hypothesis that "there would be significant difference 
between orphan and normal children in the 'inclusion' of different family members' in their family drawings is partially accepted.

\section{DISCUSSION:}

The results of the present investigation with respect to the preference to draw different family members 'first' provide enough indications to believe that the preferences of orphan and normal children towards their family members are different. The highest percentage of orphan children preferred 'sister' and 'brother' as their first drawn figures. In the case of normal children the highest percentage of children preferred 'self' as their first drawn figure, followed by 'father and brother'. The orphan and normal children experience different family conditions. The orphan children are deprived of ordinary mothering. They are placed in institutions, have no family and are completely away from ordinary family situations. As a result of this the orphan children would normally prefer other than their parents. This assumption is found to be correct as they preferred to draw first their sisters and brothers. Orphan children in institutions are very much attached to other children of their kind and this may be the reason for the orphan children to draw first their sisters and brothers in their family drawings.

The self-concept of severely deprived children will be low compared to normal children. This assumption gains strength from the results of the present investigation also. Unlike orphan children, a highest percentage of normal children have drawn their 'self' as their first drawn figure. In normal children the percentage of first drawn preference to father is almost equal to that of brother. The sister figure is less preferred when compared to brother by the normal children. Normal children might think that brother has an equal importance in the family like the father. In the Indian cultural setting, after the parents, male children are valued more than the female children, irrespective of their age. Generally, children consider father as the most important person in the family. On the whole, the orphan and normal children differ significantly with several aspects of the first drawn figure. The children preferred sister followed by brother as their first drawn figures, whereas normal children preferred to draw self as their first drawn figure followed by father in their family drawings.

The closeness of children to their family members can be known through their family drawings. Grouping of the family member gives an idea about children's preferences of the family members. Generally, children perceive their family as a unit. More normal children grouped their family members in to one group, whereas, more orphan children have drawn only one figure which comes under 'does not apply' category. This clearly shows that orphans, due to lack of family members, do not observe any close interpersonal relations with family members. Therefore the highest percentage of orphan children drew one figure. Normal children have shown similar tendency in the case of drawing all the family members as a single unit. So more normal children depicted their family members as single unit, whereas, more orphan children have not depicted grouping of their family members in their drawings. 
A child feels what he feels, rather than, what he sees or knows to be true. The child gives outward expression to his inner thoughts and feelings through his drawings. The larger figures drawn are likely to be perceived as more important than figures drawn smaller. Researcher evidence suggests that the relative size of the drawing is related to person level of self-esteem and energy. Small drawings reflect low self-esteem, depression and low level of energy. Large drawings suggest high self-esteem and high level of energy (Machover, 1949). In the preset study the maximum percentage of orphan and normal children has depicted figures that come under 'does not apply' category. These children have drawn only one family member or more than one family member as equally large in size. It is because, normal children are unable to give the first place to any of their family members. They might assume that more than one family member influences them so that they are unable to give their preference while drawing different family members as largest in size. The orphan children also depicted either a single figure or all the siblings equal in size, indicating their inability to recognize the value and importance of other family members. While drawing different family member figures largest in size the orphan and normal children differ significantly from each other with respect to self, mother and grandparents.

With regard to the 'inclusion' of different family members figures the order of preference in the case of orphan children is siblings, father, grandparents, self, mother and others. Because orphan children are deprived of their family member's love and in institution they usually treat other children as their siblings and develop attachment with them. In the case of normal children the order is brother, self, father, sister, mother, others and grandparents. The disciplinary actions and unfavorable child rearing practices imposed by parents make normal children prefer their siblings rather than their parents.

\section{CONCLUSIONS:}

1) Orphan and normal children differed significantly with respect to first drawn figure of self, father and sister. Highest percentage of orphan children preferred to draw brother and sister figures first in the sequence of family drawings. But majority of normal children preferred to draw their self figure first, followed by father and brother in the sequence of family drawings.

2) Orphan and normal children differed significantly in drawing the family members' figures in to 'one group'. Majority of normal children drew all their family members' figures in to one group.

3) Orphan and normal children differed significantly in their preference to depict self, mother, grandparents as the largest in size in the family drawings.

4) Orphan and normal children differed significantly in the inclusion of their sister and self figures in the family drawings. More orphan than normal children included sister figure, but more normal than orphan children included self figure in the family drawings. 


\section{REFERENCES:}

Bhadramani,G., Venkatachalam,J., Samiullah,S., and Sivasankara Reddy,K. (1993). Family preferences of children-A study of family drawings. Indian Journal of Applied Psychology, 30(1), 54-60.

Burns (1987). In Gray, G.M. Hand book of Psychological Assessment ( ${ }^{\text {nd }}$ Ed.), 1990. New York: John Wiley.

Freeman,H.E. and Showel,M.(1953). The role of the family in the socialization process. Journal of Social Psychology, 37, 97-101.

Goodenough, F.L.(1926). In Gray, G.M. Hand book of Psychological Assessment (2 ${ }^{\text {nd }}$ Ed.), 1990. New York: John Wiley.

Hulse (1951). In Gray, G.M. Hand book of Psychological Assessment ( $2^{\text {nd }}$ Ed.), 1990. New York: John Wiley.

Jackson,L.(1950). Emotional attitudes toward the family of normal, neurotic and delinquent children. British Journal of Psychology, 41, 173-185.

Kelly,O.G. (1984). Children's drawings as a means of non-verbal communication: An Introduction. British Journal of Occupational Therapy, 47(8), 244-246.

Kohn, M.L. (1972). Class, family and schizophrenia: A reformulation. Social forces, 50, $295-$ 304.

Machover (1949). In Gray, G.M. Hand book of Psychological Assessment (2 ${ }^{\text {nd }}$ Ed.), 1990. New York: John Wiley.

Montague, J.A. (1951). Spontaneous drawings of the human form in childhood schizophrenia. In Glady L.Anderson (Eds). An introduction to projective techniques. New York. Prentice-Hall, 370-385.

Sinha,D. (1982). Some recent changes in the Indian family and their implications for socialisation. Paper presented to the conference on 'changing family in a changing world', organized by the German convention for UNESCO, Munich.

Pryluta, R.E., and Leish, G.G.(1972). Absolute and relative figure drawing size in institutionalized orphans. Journal of Clinical Psychology, 28(3), 377-379. 
Table-1: Percentage of orphan and normal children for their preference to draw different family members 'first' and the values of significance of the difference between them.

\begin{tabular}{|l|l|l|l|}
\hline $\begin{array}{l}\text { 'First ' Drawn Family } \\
\text { Member Figure }\end{array}$ & $\begin{array}{l}\text { Percentage of Orphan } \\
\text { children preference } \\
(\mathrm{N}=105)\end{array}$ & $\begin{array}{l}\text { Percentage of Normal } \\
\text { children preference } \\
(\mathrm{N}=100)\end{array}$ & $\begin{array}{l}\mathrm{t} \text { ' } \\
\text { value }\end{array}$ \\
\hline 1) Self & 6.66 & 26 & $3.81^{* *}$ \\
\hline 2) Mother & 3.80 & 5 & $0.42 @$ \\
\hline 3) Father & 6.66 & 23 & $3.19^{* *}$ \\
\hline 4) Brother & 33.33 & 22 & $1.66 @$ \\
\hline 5) Sister & 36.19 & 12 & $4.08^{* *}$ \\
\hline 6) Grandparents & 6.66 & 3 & $1.23 @$ \\
\hline 7) Others & 6.66 & 9 & $0.63 @$ \\
\hline
\end{tabular}

**Significant at 0.01 level@ Not Significant

Table-2: Percentage of orphan and normal children for their preference in drawing different 'groupings' in their family drawings and the values of significance of the difference between them.

\begin{tabular}{|c|c|c|c|}
\hline $\begin{array}{lr}\text { Drawing } & \text { Family } \\
\text { Members } & \text { in to } \\
\text { different 'Groups' } & \end{array}$ & $\begin{array}{l}\text { Percentage of Orphan } \\
\text { children preference } \\
\qquad(\mathrm{N}=105)\end{array}$ & $\begin{array}{l}\text { Percentage of Normal } \\
\text { children preference } \\
(\mathrm{N}=100)\end{array}$ & $\begin{array}{l}\text { 't' } \\
\text { value }\end{array}$ \\
\hline 1) All in one group & 24.70 & 40 & $2.36^{*}$ \\
\hline 2) Two groups & 22.85 & 23 & $0.02 @$ \\
\hline 3) Three groups & 1.90 & 1 & $0.42 @$ \\
\hline 4) Divergence & 5.71 & 1 & $2.50 *$ \\
\hline 5)Separate compartments & 0.95 & 0 & $0.99 @$ \\
\hline 6) Does not apply & 43.80 & 35 & 1.30@ \\
\hline
\end{tabular}

*Significant at 0.05 level @ Not Significant 


\section{Study of Family Preferences of Orphan and Normal Children through Family Drawings}

Table-3: Percentage of orphan and normal children for their preference in drawing different family members' figures as the 'largest' in size and the values of significance of the difference between them.

\begin{tabular}{|l|l|l|l|}
\hline $\begin{array}{l}\text { Drawing Family members' } \\
\text { Figures as the 'largest' in } \\
\text { size }\end{array}$ & $\begin{array}{l}\text { Percentage of Orphan } \\
\text { children preference } \\
(\mathrm{N}=105)\end{array}$ & $\begin{array}{l}\text { Percentage of Normal } \\
\text { children preference } \\
(\mathrm{N}=100)\end{array}$ & $\begin{array}{l}\text { 't' } \\
\text { value }\end{array}$ \\
\hline 1) Self & 1.90 & 12 & $2.90^{* *}$ \\
\hline 2) Mother & 3.80 & 10 & $2.00^{*}$ \\
\hline 3) Father & 2.02 & 9 & $0.64 @$ \\
\hline 4) Brother & 8.57 & 6 & $0.71 @$ \\
\hline 5) Sister & 8.57 & 3 & $1.72 @$ \\
\hline 6) Grandparents & 17.52 & 5 & $3.15^{* *}$ \\
\hline 7) Others & 3.80 & 5 & $0.42 @$ \\
\hline 8) Does not apply & 43.80 & 38 & $0.32 @$ \\
\hline 9) All figures equal in size & 14.28 & 13 & $0.27 @$ \\
\hline
\end{tabular}

**Significant at 0.01 level *Significant at 0.05 level @ Not Significant

Table-4: Percentage of orphan and normal children for their preference in the 'inclusion' of different family members and the values of significance of the difference between them.

\begin{tabular}{|c|c|c|c|}
\hline $\begin{array}{l}\text { 'Inclusion' of different } \\
\text { Family Members }\end{array}$ & $\begin{array}{l}\text { Percentage of Orphan } \\
\text { children preference } \\
(\mathrm{N}=105)\end{array}$ & $\begin{array}{l}\text { Percentage of Normal } \\
\text { children preference } \\
(\mathrm{N}=100)\end{array}$ & $\begin{array}{l}\text { 't' } \\
\text { value }\end{array}$ \\
\hline 1) Self & 13.33 & 43 & $4.80 * *$ \\
\hline 2) Mother & 15.23 & 19 & 0.72@ \\
\hline 3) Father & 22.85 & 29 & $1.01 @$ \\
\hline 4) Brother & 45.71 & 45 & $1.75 @$ \\
\hline 5) Sister & 57.14 & 27 & $4.42 * *$ \\
\hline 6) Grandparents & 16.19 & 10 & $1.25 @$ \\
\hline 7) Others & 11.42 & 13 & $0.35 @$ \\
\hline 8) Does not apply & 0.00 & 0 & $0.00 @$ \\
\hline
\end{tabular}

**Significant at 0.01 level @ Not Significant 